\title{
ASESOR Y NO DEFENSOR: LA FUNCIÓN DEL ABOGADO QUE ASESORA EN PLANEAMIENTO TRIBUTARIO
}

\author{
Advisor and Non-Defensor: The Role of Lawyer Who Advises on Tax Planning
}

Alexis Luján ${ }^{1}$

\section{RESUMEN}

El autor sostiene que, en general, los abogados asumen una función social $\mathrm{y}$, por ello, tienen deberes frente a la sociedad y no solo frente a sus clientes. Además, el autor ca acteriza los distintos tipos de funciones que astumen los abogados tributaristas e identifica la función de asesor como la principal en el marco del planeamiento tributario. Bajo ese entendido, el autor explica en qué se diferencia la función de asesor de la de defensor y por qué dicha distinción es relevante para efectos del cumplimiento de las normas de responsabilidad profesional del abogado.

PALABRAS CLAVE: Planeamiento tributario ética del abogado - abogado tributarista - función del abogado - responsabilidad profesional del abogado.

\begin{abstract}
The author argues that, in general, lawyers have a social function and, as a consequence, have duties to society and not only to their clients. In addition, the author characterizes the different types of roles assumed by tax lawyers and identifies the role of advisor as the principal in the context of tax planning. Under such understanding, the author explains that the counselor role differs from lawyer role and why such difference is relevant regarding the compliance of lawyer's professional liability standards.
\end{abstract}

KEY WORDS: Tax planning - lawyer ethics

- tax lawyer- lawyer function - lawyer's professional responsibility

\footnotetext{
${ }^{1}$ Bachiller en Derecho por la Pontificia Universidad Católica del Perú. Cuenta con más de cinco años de experiencia en empresas que brindan asesoramiento tributario. Ha sido asistente del curso de Planeamiento Tributario de la Maestría en Derecho Tributario de la PUCP, así como del curso de Ética y Responsabilidad Profesional del Abogado en la Facultad de Derecho de la PUCP y en la Facultad de Derecho de la Universidad del Pacífico. Miembro del Grupo de Investigación sobre Ética y Responsabilidad Profesional del Abogado desde 2012. Miembro Extraordinario de IUS ET VERITAS.

El autor agradece los valiosos comentarios de Beatriz Boza profesora del curso de Ética y Responsabilidad Profesional del Abogado en la Facultad de Derecho de la Pontificia Universidad Católica del Perú. Además, deja constancia de que las opiniones expresadas en este ensayo, así como cualquier error u omisión, son de su exclusiva responsabilidad y que, de ninguna manera, comprometen la opinión de las organizaciones que conforma. Cualquier crítica, sugerencia o comentario con relación al contenido del presente ensayo puede ser dirigido al correo electrónico alexis.lujan@pucp.pe.
} 


\section{INTRODUCCIÓN}

Recientes escándalos internacionales más conocidos como Paradise Papers (2017), Panama Papers (2016) y Swissleaks (2014), así como las investigaciones que algunos Estados siguen a grandes transnacionales (como Apple, Starbucks, Fiat, Google, etc.) por supuestos casos de "elusión tributaria" vienen planteando serios cuestionamientos a los sistemas tributarios modernos que han alcanzado dimensiones globales.

Distinguir entre conductas que generan ventajas tributarias legítimas respecto de otras que vienen siendo rechazadas por los Estados, y que conforman el fenómeno conocido como elusión tributaria, suele ser, en muchos casos, un asunto complejo y sujeto a distintas interpretaciones. ${ }^{2}$ Por ello, algo que no pasó desapercibido en los casos antes mencionados es que algunas de las empresas o ciudadanos involucrados no actuaron sin recibir asesoría previa, sino justamente considerando la opinión o consejo de un abogado.

Siendo que la asesoría que brindan los abogados, en muchos casos, consiste en dar una opinión sobre zonas grises en el ordenamiento jurídico, una cuestión sumamente relevante -que, por cierto, es bastante compleja y no pretendemos agotar en este breve ensayo- es si basta que existan ciertos argumentos que abonen a una interpretación para que los abogados respalden su opinión en esta o si la normativa profesional les exige amparar su opinión en una interpretación cuyos argumentos tengan cierto nivel de solidez.

Desde nuestro punto de vista, una cuestión relevante en el análisis de la problemática mencionada es si la función que cumplen los abogados al asesorar en planeamiento tributario consiste en: (i) defender una interpretación favorable a su cliente; es decir, si el abogado debe actuar como un "defensor"; o, (ii) evaluar los riesgos y ventajas asociados a las distintas interpretaciones a fin de ayudar a su cliente a tomar una decisión; en otras palabras, si el abogado debe actuar como un "asesor".

En efecto, si, a partir del análisis de la normativa profesional, se concluye que el abogado asume la función de "defensor" al asesorar en planeamiento tributario cabrían elementos para sostener que basta que la interpretación que sustenta su opinión esté respaldada en ciertos argumentos aun cuando estos no tengan un nivel de solidez relevante.

En cambio, si se concluye que el abogado cumple la función de "asesor" habría elementos para sostener que la solidez de los argumentos que soportan su opinión debería ser mayor a aquella que se le exigiría para la defensa en una controversia frente a la autoridad tributaria.

En este ensayo buscamos dar respuesta a esta última cuestión. Para ello, dado que se trata de un asunto que no ha sido abordado expresamente por el Código de Ética del Abogado de 2012, el desarrollo de nuestra posición estará sustentado principalmente en un análisis de dos de sus instituciones esenciales: el deber de patrocinio celoso del interés del cliente y la misión de la profesión.

\section{EL ABOGADO TRIBUTARISTA COMO "ASESOR TRIBUTARIO"}

La "tributación" es una disciplina bastante compleja y eso ha llevado a que sea un terreno compartido entre profesionales de distintas áreas (principalmente contadores, abogados y economistas) siendo incluso que en algunos países

\footnotetext{
Si bien los Estados modernos reconocen que los contribuyentes pueden escoger entre las distintas opciones que les proporciona el ordenamiento jurídico aquellas que les generan una menor carga tributaria, al mismo tiempo, rechazan algunas conductas a través de las cuales los contribuyentes podrían conseguir ventajas tributarias. En el Perú, por ejemplo, se combate la elusión tributaria entendida como el uso de hechos o negocios que resultan artificiosos o impropios respecto de otros que hubieran tenido efectos jurídicos y económicos iguales o similares, pero consecuencias tributarias más gravosas.
} 
se reconoce la profesión de "asesor tributario" como una independiente y sujeta a una regulación específica. $^{3}$

Cabría preguntarnos, por ello, lo siguiente: ¿tienen los abogados "algo" que los distinga del resto de asesores tributarios? ¿En algún caso resulta imprescindible la participación de un abogado como asesor tributario y no la de otro profesional? Veamos.

Como hemos señalado en un ensayo previo (Luján, 2018), el abogado es el profesional a quien la sociedad le confía la tarea de comprender y hacer comprender a otros, a través de la palabra, cómo los hechos se relacionan con el derecho. Como señala Alzamora Valdez, para elevarlos hasta alli y no para acomodar un supuesto derecho a los hechos -como en la práctica muchas veces ocurre. ${ }^{4}$

De lo anterior se desprende que lo que distingue a los abogados de otros profesionales cuya actuación es relevante en el ámbito tributario es que la sociedad les confía el ejercicio de una actividad consistente en usar conocimientos sobre el ordenamiento jurídico. ${ }^{5}$ Por ello, el rol del abogado no es equiparable al de contadores, economistas u otros profesionales.
La participación de un contador resultaría ineludible, por ejemplo, para identificar en forma precisa la información contable que debe utilizarse para determinar los tributos y de esa forma evitar omisiones en el pago de impuestos o realizar pagos en exceso. La participación de un economista resultaría necesaria para cumplir normas de valoración para la determinación de los impuestos. Por ejemplo, verificar si la contraprestación de una transacción o la utilidad de una empresa se encuentra dentro de valores de mercado.

Ahora bien, lo difícil muchas veces no es realizar las operaciones matemáticas necesarias para calcular un tributo, entender la contabilidad de una empresa o verificar si una transacción o utilidad es consistente con los valores de mercado, sino descifrar (y aplicar a hechos concretos) una normativa tributaria técnica, compleja, abundante, poco -o mal- sistematizada y en muchos casos hasta ambigua o contradictoria.

Tener un sistema tributario estructurado sobre la base de normas complejas genera una demanda de abogados especializados en el entendimiento de las normas tributarias a los que suele llamárseles abogados "tributaristas" que, en tanto abogados, deben cumplir con la misión y deberes propios de los profesionales del Derecho.

3 En el Perú no se exige ningún requisito específico para prestar servicios de asesoramiento tributario a diferencia de lo que ocurre, por ejemplo, en Estados Unidos. En el Perú, entonces, cualquier persona puede desempeñarse como "asesor tributario", aunque son los abogados y contadores quienes lo hacen principalmente.

${ }^{4}$ Alzamora (2000) lo explica de la forma siguiente: "[C]ualquiera que sea el ámbito en que actúe, el abogado no pierde sus características esenciales a no ser que no realice las funciones de tal. La economía, el comercio, la política, la universidad le abren sus puertas pero en todos estos sectores de la vida tiene el imperativo no de acomodar un supuesto derecho a los hechos sino de elevar los hechos hasta ese reino intemporal y eterno de la justicia y del derecho. [...] Tal es la misión y la ambición del abogado: elevar los hechos para lograr el ideal del derecho"' (p. 550-553).

${ }^{5}$ La sociedad confía en los abogados el uso de conocimientos técnicos sobre el ordenamiento jurídico en un contexto en el que el resto de ciudadanos, como regla general, lo desconoce. Por eso se justifica que la sociedad regule el uso de los mencionados conocimientos imponiendo a los abogados ciertos límites que en el Perú están contemplados, principalmente, en el Código de Ética del Abogado de 2012.

En consecuencia, el abogado debe usar dichos conocimientos en forma responsable y con el objeto de cumplir su misión. De la misma forma en que la sociedad rechaza que un médico, profesional de la salud, utilice sus conocimientos sobre el cuerpo humano para atentar contra la salud de las personas, la sociedad no faculta al abogado, profesional del derecho, a usar sus conocimientos para atentar contra las instituciones del Estado constitucional de derecho. 


\section{EL ROL QUE CUMPLE EL} ABOGADO TRIBUTARISTA

Según la OCDE (2008), el rol que cumplen en la sociedad los asesores tributarios en general (abogados, contadores, economistas y otros) es ayudar a los ciudadanos a comprender las abundantes, complejas y cambiantes normas tributarias (situación que, por cierto, es creada por el propio Estado). De esa forma al ayudar a que no se pague menos de lo que se debe e impedir, a través de su consejo, que se cometan infracciones $\mathrm{y}$ delitos los asesores tributarios contribuyen al sostenimiento de los gastos públicos.

Particularmente, en el caso de los asesores tributarios que son abogados habría que tener en cuenta que su misión, desde nuestro punto de vista, no se limita a la defensa del interés de su cliente sino que también apunta a la consolidación del Estado constitucional de derecho. ${ }^{6}$ Por ello, acertadamente se ha dicho que el abogado "representa al cliente ante el sistema jurídico, pero también representa al sistema jurídico ante el cliente"'(Gordon, 1999, 173). ${ }^{7}$

En efecto, la actuación del abogado resulta relevante tanto para el cliente como para la sociedad lo cual evidencia que este cumple una función social:

- Para el cliente: Ante la existencia de espacios inciertos en la normativa tributaria, para un contribuyente es importante recurrir a la opinión de un abogado para exonerarse de responsabilidad si las autoridades acogen una interpretación distinta a la suya o, al menos, para reducir el riesgo de que ello ocurra. $^{8}$

En el curso normal de los negocios, las personas y empresas no actúan en contra de la opinión de su asesor legal. ${ }^{9}$ Por ello, la opinión del abogado sobre la interpretación de las normas constituye un filtro esencial en la toma de decisiones del contribuyente.

- Para la sociedad: La recaudación tributaria se sostiene principalmente en el régimen de

${ }^{6}$ En el Perú los abogados no son funcionarios públicos u oficiales de la corte, pero el mayor entendimiento que tienen del ordenamiento jurídico los coloca en una posición que les permite evitar conductas indebidas desde el interior de las organizaciones y los convierte en verdaderos garantes del ordenamiento jurídico (Luján, 2018). Así, la misión del abogado no se agota en la defensa del interés de su cliente, sino que trasciende a ello, por lo cual, en el Artículo 3 del Código de Ética del Abogado se señala con claridad que la abogacía tiene como fines "la defensa de los derechos de las personas y la consolidación del Estado de Derecho; lajusticia y el orden social".

7 Nótese que la misión dual del abogado lleva al surgimiento de deberes frente a su cliente y frente a la sociedad. Por ello, el abogado muchas veces se encuentra en el ejercicio profesional frente a dilemas cuya resolución, en cada caso concreto, le exige evaluar no solo aquello que su cliente espera que haga, sino también lo que la sociedad espera de él.

8 Algunos sistemas legales exigen culpabilidad (responsabilidad subjetiva) para que proceda la aplicación de sanciones tributarias. En estos sistemas, un contribuyente puede aducir haber actuado de buena fe al seguir la consejería de sus abogados para evitar eventuales multas en caso se confirme la posición de la Administración Tributaria en el marco de una controversia (por ejemplo, ello ocurre en Estados Unidos). Como correlato, actuar en contra de lo señalado por un asesor legal podría ameritar una reacción más severa por parte del ordenamiento jurídico (por ejemplo, cuando un juez debe determinar la responsabilidad de un funcionario u órgano de administración de una sociedad).

En cambio, en un sistema de responsabilidad objetiva, tener respaldo en una opinión jurídica también resulta trascedente para los contribuyentes. Los contribuyentes, en el curso normal de los negocios, recurren a los abogados -que son los especialistas en el entendimiento de las leyes, para conocer el nivel de riesgo asociado a ciertas posiciones tributarias y de esa forma disminuir el riesgo de eventuales sanciones.

En el Perú, el Código Tributario señala que la aplicación de sanciones es objetiva, no obstante, este asunto se viene discutiendo en el Poder Judicial y, existen ya pronunciamientos, en los que se ha señalado que debe verificarse la existencia de culpabilidad por parte del contribuyente.

9 En el caso de las personas jurídicas, actuar en forma contraria a lo recomendado por el asesor legal podría generar responsabilidades en los órganos y funcionarios que toman las decisiones respectivas. 
autodeterminación (cada contribuyente determina y declara el tributo a su cargo y el Estado fiscaliza en forma posterior algunas declaraciones), por ello, la opinión que da el abogado tributarista a su cliente también resulta trascendente. ${ }^{10}$

Dado que el Estado no puede fiscalizar todas las declaraciones de impuestos (tampoco sería eficiente que lo haga) la recaudación del Estado depende en gran medida de que los contribuyentes determinen en forma correcta la obligación tributaria que tienen a su cargo. ${ }^{11}$

En ese escenario, a pesar de no ser un funcionario del Estado, el abogado tributarista cumple un rol esencial en favor de la sociedad: al guiar a su cliente a descifrar la normativa tributaria, en el agregado, termina custodiando no solo el interés de su cliente, sino también la recaudación del Estado. $^{12}$

Ahora bien, ¿qué tipo de servicios brinda un abogado tributarista? ¿En qué se diferencian de los servicios que brindan otros abogados? ¿Asume el abogado tributarista la misma función al prestar dichos servicios a sus clientes? Veamos.

\section{LAS DIFERENTES FUNCIONES QUE ASUME EL ABOGADO TRIBUTARISTA AL PRESTAR SERVICIOS}

Los servicios que en la práctica privada prestan los tributaristas son similares a aquellos que brindan los abogados especializados en otras materias. ${ }^{13}$ En efecto, es común que, en general, los abogados realicen tareas como las siguientes:

a. Defender el interés de su cliente ante las autoridades de cara a una decisión pública,

b. Brindar asesoramiento con relación a las consecuencias legales de hechos o negocios,

c. Participar en la negociación y, de ser el caso, elaboración de contratos,

d. Verificar el cumplimiento de las normas; o,

e. Patrocinar procesos o procedimientos contenciosos y no contenciosos.

$\mathrm{Al}$ prestar sus servicios, los abogados tributaristas realizan actividades como las antes mencionadas, pero con la particularidad de que: (i) lo que está en juego es la aplicación de normas tributarias (sean sustantivas o procedimentales); y, (ii) usualmente la contraparte del cliente es el Estado, en tanto, acreedor de un tributo.

Es posible identificar que, en mayor o menor medida, los tributaristas asumen al prestar sus servicios distintas funciones como, por ejemplo, la de asesor, defensor, negociador o evaluador. El Preámbulo de las Reglas Modelo de Conducta Profesional de la American Bar Association

10 El régimen de autodeterminación parte de una situación en la que existe asimetría informativa. El contribuyente cuenta con la información que el Estado necesita para verificar que esté cumpliendo adecuadamente con la obligación de pagar el impuesto y es escasa la información que el Estado puede obtener por otras fuentes.

1 Si nunca llega a fiscalizarse una declaración de impuestos, esta queda convalidada transcurrido el plazo de prescripción de la facultad de la administración para determinar el tributo.

12 Por todo lo anterior, tiene razón Caplin (2005) al señalar: (i) que la competencia y diligencia profesional, la integridad y los estándares de conducta de los abogados guardarían relación directa con el cumplimiento tributario y el propio concepto de autodeterminación; $y$, (ii) que el adecuado funcionamiento del sistema tributario dependería en cierta medida de los abogados.

${ }^{13}$ En este ensayo, nos estamos enfocando en el patrocinio de clientes en el ámbito privado; sin embargo, es preciso aclarar que la labor de un abogado tributarista es más amplia, ya que puede abarcar muchos otros campos. Así, por ejemplo, el abogado tributarista puede hacer las veces de gerente legal, gestor de intereses, asesor de congresistas, funcionario público o juez. El rol que el abogado asume en cada uno de estos campos de actuación podría presentar algunas particularidades cuyo estudio no es objeto de nuestra investigación, ya que estamos limitando nuestro análisis principalmente a lo que se ha venido en denominar comúnmente como la práctica privada. 
[ABA] (2004) resume en forma didáctica en qué consisten dichas funciones en la práctica privada:

"Como representante de sus clientes, un abogado desempeña distintas funciones. Como asesor, un abogado proporciona a su cliente una comprensión informada de sus derechos $y$ obligaciones y le explica sus implicaciones prácticas. Como defensor, un abogado defiende con celo la posición del cliente bajo las reglas del sistema adversarial. Como negociador, un abogado busca un resultado ventajoso para su cliente, pero consistente con las exigencias de dar un trato honesto a los demás. Como evaluador, un abogado actúa examinando los asuntos legales de un cliente e informando sobre ellos al cliente o a otros". ${ }^{14}$

En el siguiente cuadro brindamos ejemplos de servicios que realizan los tributaristas y cómo estos se distinguen respecto de la oportunidad en la que estas suelen ser requeridos de cara a un hecho relevante para el cliente, el interés que tiene el cliente al contratar al abogado y la función o funciones que este asumiría en atención a las características de tales servicios.

\section{Ejemplos de servicios que brinda el abogado tributarista y diferencias entre ellos}

Elaboración propia.

En resumen, la labor del abogado resulta necesaria en el ámbito tributario y le exige asumir diferentes funciones, según el tipo de servicio que brinde. No es nuestro propósito analizar en este ensayo el rol que asume el abogado en cada una de dichas funciones, sino específicamente la que asume cuando asesora en planeamiento tributario.

Por lo antes mencionado, las siguientes preguntas resultan relevantes: ¿el hecho de que el abogado tenga una función social significa que al interpretar las leyes en el marco de una asesoría deba asumir una posición a favor del Estado? ¿Cómo debe actuar cuando debe emitir una opinión sobre un asunto que resulta discutible? ¿Debe informar y recomendar únicamente la posición que más favorece a su cliente? Veamos.

\section{LA FUNCIÓN DEL ABOGADO AL ASESORAR EN PLANEAMIENTO TRIBUTARIO}

El Código de Ética del Abogado de 2012 no incorpora normas que explícitamente señalen que el abogado que asesora en planeamiento tributario asume una función de asesor y no de defensor. Sin embargo, desde nuestro punto de vista, ello se desprendería de un análisis del deber de patrocinio celoso del interés del cliente y de una interpretación consistente con la misión del abogado. Veamos.

Cumplir adecuadamente la normativa tributaria implica pagar lo que es debido. Eso no significa que, entre las distintas opciones previstas por el ordenamiento, un contribuyente deba escoger aquella que le resulta más onerosa desde una perspectiva fiscal. Una adecuada planificación puede permitir ahorros tributarios legítimos. ${ }^{15}$

${ }^{14}$ Cabe indicar que en este artículo tomamos como referencia lo señalado en el Preámbulo de las Reglas Modelo de Conducta Profesional de la ABA de Estados Unidos (así como la opinión de autores norteamericanos) como un elemento útil para guiar una interpretación de las normas del Código de Ética del Abogado de 2012 en razón del sustento lógico de su contenido y no como si se tratara de una norma de aplicación supletoria.

No está demás señalar que, en el año 2012, la Junta de Decanos de los colegios de abogados del país promulgó el Código de Ética del Abogado cuya redacción fue elaborada sobre la base del Código Voluntario de Buenas Prácticas del Abogado de la Red Peruana de Universidades y del Proyecto de Código de Ética y Responsabilidad del Profesional en Derecho. Estos dos últimos documentos fueron producto de un esfuerzo académico liderado por Beatriz Boza que implicó la revisión de diversas referencias internacionales entre las cuales se incluyen las Reglas Modelo de Conducta Profesional de la ABA.

${ }^{15}$ Piénsese, por ejemplo, en aquellos ahorros que derivan de un uso adecuado de las propias alternativas que las normas brindan a los contribuyentes para determinar sus impuestos. 
En algunos casos el conocimiento de las normas tributarias permite que el abogado asista a su cliente a cumplirlas sin tener que asumir una mayor carga fiscal que, la que en estricto, le corresponde. Sin embargo, existen espacios en la normativa que admiten más de una interpretación y tienen la potencialidad de originar controversias cuyo resultado es incierto.

Pensamos que, frente a espacios de incertidumbre como los antes mencionados, la oportunidad en la que asume el encargo determina que el abogado que actúa como asesor tenga un rol distinto al de aquél que es contratado para defender un caso.

El abogado asesor actúa antes de la toma de decisiones por parte de los contribuyentes e incluso, en el caso del planeamiento tributario, por definición, en forma previa a la realización de las operaciones respectivas. En cambio, el abogado contratado para patrocinar en un procedimiento defiende frente a la Administración Tributaria una interpretación previamente asumida por su cliente.

Esta distinción es relevante tanto si se analiza desde la perspectiva del cliente como si se hace desde la perspectiva del Estado:

- Para el cliente: En general el cliente espera que el abogado le brinde una consejería que le permita evaluar todas las consecuencias legales de su actuar (incluyendo la posibilidad de disminuir los potenciales riesgos de una eventual fiscalización). ${ }^{16}$

Desde nuestro punto de vista, una defensa celosa del interés del cliente exige que el abogado le informe a este sobre las distintas interpretaciones que admite la ley y el riesgo asociado a cada una y no que asuma como suya o recomiende, entre todas las interpretaciones posibles, aquella que beneficia de mejor forma a su cliente.

Para el Estado: El abogado actúa en un momento en el que es incierto si la declaración jurada del contribuyente (su cliente) será fiscalizada y en el que existe la posibilidad de evitar una controversia entre el contribuyente y la Administración Tributaria. ${ }^{17}$

Por ello, de cara al sistema de recaudación de tributos, no resultaría aconsejable que el abogado recomiende posiciones sobre la interpretación de las normas que estén soportadas en escasos o nulos argumentos, ya que, de lo contrario, en los hechos, estas podrían prevalecer no por su solidez técnica sino por la ausencia de una fiscalización llevando a que la actuación del abogado no sea consistente con la misión de su profesión.

Por lo anterior, tendemos a pensar que un adecuado balance entre lo que el cliente y la sociedad esperan del abogado como asesor lleva a concluir que este no debería asumir en estricto el rol de defensor de una interpretación determinada, sino evaluar los méritos de dicha interpretación a fin de informar a su cliente sobre los posibles riesgos y ventajas de asumir tal interpretación.

Bajo dicha perspectiva, al momento de recomendar una interpretación, el abogado debe evaluar las posibilidades con las que esta cuenta de ser aceptada por las autoridades tributarias. Así, el abogado tendría que ponderar los argumentos que sustentan las distintas interpretaciones admisibles casi como si fuera un juez y no únicamente como un defensor de la posición que más le conviene a su cliente.

\footnotetext{
${ }^{16}$ Algunos clientes podrían incluso preferir pagar un importe mayor a aquél que las normas tributarias exigen con tal de obtener una seguridad y previsibilidad para sus inversiones. Bajo esa premisa, por ejemplo, en los sectores de hidrocarburos y minería se admite la celebración de contratos de estabilidad considerando una tasa de impuesto a la renta mayor a la de aplicación general.

${ }^{17}$ Ello, puesto que al tiempo del asesoramiento tributario no se han generado los hechos y negocios que dan lugar a la obligación tributaria.
} 
Entender este planteamiento resulta indispensable para identificar los deberes del abogado que asesora en planeamiento tributario. En efecto, como bien señala Wolfman (2015, p. 2): " $[e] l$ deber de defender celosamente el interés del cliente podría dominar cuando el abogado actúa como defensor ante la corte. En el rol de rol de asesor, el deber del abogado frente al sistema podría requerir que reprima el celo frente a la causa del cliente, al menos hasta cierto punto". ${ }^{18}$

Entonces, desde nuestro punto de vista, a partir de una interpretación del Código de Ética del Abogado acorde con el deber de patrocinio celoso del cliente y la misión de la profesión, es posible sostener que el abogado asume la función de "asesor" y no la de "defensor" al asesorar en planeamiento tributario.

Por ello, desde nuestro punto de vista, además, existirían elementos para sostener que la solidez de los argumentos que soportan la opinión de un abogado en el marco de una asesoría en planeamiento tributario debería ser mayor a aquella que sería aceptable en el marco de la defensa en una controversia frente a la autoridad tributaria.

De otro lado, pensamos que lo antes mencionado abonaría a la vez elementos para sostener que, en el marco de un planeamiento tributario, el abogado podría tener que reprimir en cierta medida el deber de patrocinio celoso del interés del cliente $\mathrm{y}$, por tanto, abstenerse de recomendar algunas interpretaciones de las normas que carezcan de un sustento técnico lo suficientemente sólido. El análisis de esta última cuestión, sin embargo, -como hemos indicado- reviste una complejidad mayor que no es objeto de desarrollo en este ensayo.

\section{A MANERA DE CONCLUSIÓN}

Los recientes escándalos internacionales que mencionamos a inicios de este artículo están llevando al mundo a repensar los sistemas tributarios. Bajo esa perspectiva, se elaboraron, por ejemplo, las 15 acciones del Proyecto de la OCDE sobre la Erosión de la Base Imponible y el Traslado de Beneficios ${ }^{19}$ (Proyecto "BEPS") (OCDE, 2015) que recomiendan acciones individuales y conjuntas ${ }^{20}$ para hacer frente a la denominada "elusión tributaria". ${ }^{21}$

El Proyecto BEPS aborda la problemática de la elusión tributaria principalmente desde la perspectiva del contribuyente, sin embargo, ha puesto también atención a las conductas de los asesores tributarios. Así, por ejemplo, la acción 12 del Proyecto BEPS apunta a la divulgación de estrategias fiscales agresivas (transfronterizas) por parte de contribuyentes y sus "promotores" (identificados como los asesores tributarios).

No debe perderse de vista, no obstante, que el Proyecto BEPS comprende recomendaciones dirigidas a elevar el estándar de la normativa tributaria, no el de la regulación profesional. Por ello, cabe preguntarnos: ¿es necesario repensar también los estándares deontológicos de la abogacía? ¿Puede por sí solo el Proyecto BEPS

${ }^{18}$ Obsérvese que, si bien el autor citado indica que se requiere examinar el desempeño del abogado en el contexto en el que actúa y evaluar sus deberes en ese marco, reconoce que la dicotomía asesor-defensor resulta útil como herramienta de análisis.

${ }^{19}$ El Plan BEPS fue impulsado por los países del G-20 y formula recomendaciones para una serie de situaciones percibidas como un problema en los sistemas tributarios del mundo.

La importancia de las 15 acciones del Plan BEPS es tal que se viene señalando en distintos medios académicos que marcaría el inicio de un nuevo orden en materia tributaria.

${ }^{20}$ Como la implementación de un Convenio para el Intercambio Automático de Información entre Estados y la Convención multilateral para aplicar las medidas relacionadas con los tratados fiscales para prevenir la erosión de las bases imponibles y el traslado de beneficio.

${ }^{21}$ De acuerdo con lo indicado en el resumen de los Informes Finales de las 15 acciones del Plan BEPS (OCDE, 2015), la elusión tributaria venía disminuyendo la recaudación mundial de los impuestos sobre las ganancias entre 100 mil y 240 mil millones de dólares anuales. 
tener un impacto real en la forma en la que los abogados brindan asesoramiento tributario? Son preguntas que ameritan una evaluación profunda y que estarán presentes en el debate académico.

\section{REFERENCIAS BIBLIOGRÁFICAS}

-Alzamora, M. (2000). La profesión del abogado. En: Chanamé Orbe, Raúl. Aprendamos a ser abogados. Lima: Editorial Praxis.

-American Bar Association. (2013). Reglas Modelo de Conducta Profesional. Disponible en: https://www.americanbar.org.

-Caplin, M. (2005) The Tax Lawyer's Role in the Way the American Tax System Works. University of Virginia School of Law. Tax Notes, Vol. 106, No. 6.

-Gordon, R. (1999). "La práctica del derecho empresarial como servicio público". En Böhmer, M. (compilador): La enseñanza del derecho y el ejercicio de la abogacía. Gedisa. Barcelona. Citado por Gonzales, G. (2015). “Abogados y globalización en el Perú (19902014)". Parlamento y Constitución. Anuario. Universidad de Castilla-La Mancha.
-Luján, A. (2018). La misión del abogado en el Estado constitucional de derecho. En: Legis.pe. 23 de febrero de 2018. Recuperado el 25 de noviembre de 2018 de: <https://legis.pe/misionabogado-estado-constitucional-derecho/>.

-OCDE. (2008). Comunicado de Ciudad del Cabo: Cuarta Reunión del Foro OCDE de Administración Tributaria. Enero de 2008.

-OECD. (2015). Reportes finales del Proyecto OCDE/G20 de Erosión de Bases Imponibles y Traslado de Beneficios, OCDE.

-Wolfman, Schenk \& Ring. (2015). Ethical Problems in Federal Tax Practice. Wolters Kluwer. Fifth Edition. 
Ejemplos

Oportunidad

nterés del cliente

Función del abogado

\begin{tabular}{|c|c|c|c|c|}
\hline 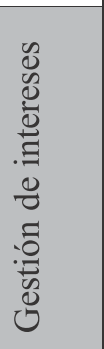 & $\begin{array}{l}\text { Exponer la posición del } \\
\text { cliente ante autoridades o } \\
\text { ante la opinión pública, } \\
\text { elaborar un proyecto de ley o } \\
\text { norma reglamentaria, evaluar } \\
\text { las consecuencias de una } \\
\text { propuesta legislativa, entre } \\
\text { otros. }^{1}\end{array}$ & $\begin{array}{l}\text { Antes de la } \\
\text { emisión de una } \\
\text { norma o } \\
\text { decisión } \\
\text { administrativa. }\end{array}$ & $\begin{array}{l}\text { Influir en una decisión } \\
\text { pública con miras a } \\
\text { resguardar sus } \\
\text { intereses. }\end{array}$ & $\begin{array}{l}\text { Defensor del interés } \\
\text { del cliente frente a } \\
\text { una decisión pública, } \\
\text { pero eventualmente } \\
\text { también negociador. }\end{array}$ \\
\hline 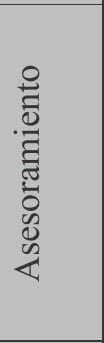 & $\begin{array}{l}\text { Elaborar una estrategia de } \\
\text { planeamiento tributario, } \\
\text { brindar una opinión sobre la } \\
\text { interpretación de una norma, } \\
\text { asistir en la negociación de } \\
\text { una transacción, entre otros. }\end{array}$ & $\begin{array}{l}\text { Antes, durante } \\
\text { o después de la } \\
\text { realización de } \\
\text { una o más } \\
\text { transacciones. }\end{array}$ & $\begin{array}{l}\text { Conocer las } \\
\text { consecuencias } \\
\text { tributarias de las } \\
\text { transacciones para } \\
\text { facilitar la toma de } \\
\text { decisiones. }\end{array}$ & $\begin{array}{l}\text { Asesor (describe } \\
\text { consecuencias de las } \\
\text { transacciones o } \\
\text { analiza escenarios } \\
\text { para optimizar la } \\
\text { carga fiscal) y } \\
\text { eventualmente } \\
\text { negociador. }\end{array}$ \\
\hline 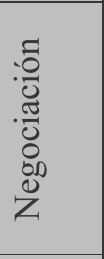 & $\begin{array}{l}\text { Acompañar en la } \\
\text { negociación de una fusión o } \\
\text { adquisición, un } \\
\text { financiamiento, una } \\
\text { transacción extrajudicial, } \\
\text { entre otros. }\end{array}$ & $\begin{array}{l}\text { Durante la } \\
\text { realización de } \\
\text { una } \\
\text { transacción. }\end{array}$ & $\begin{array}{l}\text { Obtener un acuerdo } \\
\text { que permita resguardar } \\
\text { sus intereses. }\end{array}$ & $\begin{array}{l}\text { Negociador y, en } \\
\text { cierta medida, } \\
\text { también asesor. }\end{array}$ \\
\hline 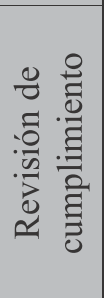 & $\begin{array}{l}\text { Revisar una declaración de } \\
\text { impuestos antes o luego de } \\
\text { su presentación, verificar el } \\
\text { cumplimiento de } \\
\text { obligaciones formales, asistir } \\
\text { en un "due diligence", etc. }\end{array}$ & $\begin{array}{l}\text { Después de la } \\
\text { realización de } \\
\text { una o más } \\
\text { transacciones. }\end{array}$ & $\begin{array}{l}\text { Verificar que las } \\
\text { normas se estén } \\
\text { cumpliendo } \\
\text { apropiadamente para } \\
\text { reducir el riesgo de } \\
\text { deudas y sanciones } \\
\text { tributarias. }\end{array}$ & $\begin{array}{l}\text { Evaluador, pero } \\
\text { también asesor e } \\
\text { incluso defensor (por } \\
\text { ejemplo, si el } \\
\text { abogado se anticipa a } \\
\text { una controversia). }\end{array}$ \\
\hline 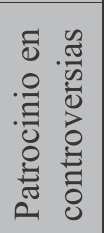 & $\begin{array}{l}\text { Brindar asistencia en la } \\
\text { obtención de una devolución } \\
\text { de impuestos, en una } \\
\text { fiscalización, en una } \\
\text { controversia, entre otros. }\end{array}$ & $\begin{array}{l}\text { Antes o } \\
\text { durante un } \\
\text { proceso o } \\
\text { procedimiento } \\
\text { tributario. }\end{array}$ & $\begin{array}{l}\text { Defender la posición } \\
\text { del cliente con relación } \\
\text { a la aplicación de las } \\
\text { normas tributarias. }\end{array}$ & $\begin{array}{l}\text { Defensor de la } \\
\text { posición del cliente } \\
\text { frente a la autoridad } \\
\text { tributaria y ante los } \\
\text { jueces. }\end{array}$ \\
\hline
\end{tabular}

